\title{
Fetal monster-induced Dystocia in a four-year-old Sokoto Gudali cow
}

\author{
${ }^{1 *}$ Ochube G.E, ${ }^{2}$ Kaltungo B.Y, ${ }^{1}$ Andrew, A. \& ${ }^{2}$ Usman, B. \\ ${ }^{1}$ Department of Veterinary Surgery and Radiology, ${ }^{2}$ Veterinary Teaching Hospital, Ahmadu Bello University, Zaria, Nigeria
}

*Corresponding author: gabrielochube2000@gmail.com; +2348035969048

\begin{abstract}
A pregnant primer cow reported to be in labor 12 hours prior to presentation was brought into the large animal clinic of the Veterinary Teaching Hospital of the Ahmadu Bello University, Zaria and was referred to the emergency unit of our facility. Examination revealed intermittent straining, serosanguinous discharge from the vulva, one fore left limb protruding from the vulva. Rectal palpation revealed an extra-large head (which felt conjoined) presented posteriorly with two separate oral cavities exhibiting suckling reflexes. Ultrasound confirmed a double rib cage with heartbeat emanating from two different locations. A tentative diagnosis of dystocia caused by fetal monster was made. Caesarian section was therefore carried out according to standard surgical procedure. The fetus died few hours later. The dam recovered post-surgery and calved a healthy calf two and a half years later.
\end{abstract}

Keywords: Caesarian section, dystocia, fetal monster, intermittent straining, rectal palpation.

\section{INTRODUCTION}

Dystocia is commonly known as difficult calving for over eight (8) hours of labor which can cause calf death at or shortly after delivery and leads to uterine infection, retained placenta and economic loss (Werber, 2013). There are three clear stages of labor in cattle; first stage lasts between 2 to 6 hours and the second stage last between 30 minutes to an hour and the final stage, which is placental expulsion could last up to 24 hours after calving (Hartman, 2012). The causes of dystocia are generally classified into maternal and fetal causes. Dystocia due to maternal causes can further be grouped as either due to constriction/obstruction of the birth canal or because of failure of the maternal repulsive force (Hartman, 2012). Causes of the constriction/obstruction of the birth canal can be narrow pelvis, uterine tumors, incomplete cervical dilatation and uterine torsion, while causes due to failure of the maternal expulsive force include primary uterine inertia, secondary to uterine tear and uterine rupture. Fetal causes of dystocia can be oversize and maldisposition of the fetus (Mcfarland, 2013).

Signs and symptoms include prolonged and non-progressive first stage labor, the cow may stand with a dipped back posture, straining vigorously for 30 minutes without the appearance of the calf, failure of the calf to be delivered within 24 hours of the amnion appearing at the vulva and obvious maldisposition (Johansson, 2014).

There are several methods of management of dystocia (fetotomy, manipulation and traction, episiotomy, caesarian section) it is advisable to conduct a caesarian section if the birth canal is too narrow and/or it is coupled with foetal maldisposition. Although foetal maldisposition can be corrected by repulsion, version and adjustment of extremities, but caesarian section is always the last option. The present case report put on record of an emergency case of dystocia as a result of fetal monster managed successfully by caesarian section in 4 year old Sokoto Gudali.

\section{CASE REPORT}

\section{HISTORY}

A 4 year old Sokoto Gudali cow weighing $250 \mathrm{~kg}$ was brought to the large animal unit of the Veterinary Teaching Hospital, Ahmadu Bello University, Zaria on $16^{\text {th }}$ March, 2019 with primary complaint of being in labor for the past 12 hours. History revealed that the animal was a primer that was managed by semi-intensive system. Intermittent straining was noticed as well as serosanguinous discharge from the 
vulva, red and swollen vulva, a left fetal forelimb protruding from the vulva (Plate I), slight emaciation, rough hair coat and patient lying on lateral recumbency.

\section{PHYSICAL AND CLINICAL EXAMINATION}

On physical examination, there was elevated pulse rate, normal respiratory rate and mild hypothermia (Table I). Other clinical signs were slight blepharospasms, salivation and bruxism. Management of the case commenced by a trans- rectal palpation which revealed extra-large head with two separate oral cavities exhibiting suckling reflexes. Ultrasound examination showed an enlarged uterus containing a hyperechogenic mass (fetus) with anachogenic region (amniotic fluid) and plancentomes. It also revealed double rib cage with heartbeat emanating from two different locations (Figure IB). Based on the above findings alongside the clinical signs, a diagnosis of a double headed fetal monster was arrived at. Haemogram of the patient was carried out which revealed no abnormal findings (Table II).

\section{SURGICAL INTERVENTION}

The patient was placed on right lateral recumbency, left abdominal flank was washed liberally with water and antiseptic soap $\left(\right.$ Dettol $\left.^{\circledR}\right)$. The ventral abdomen was shaved from the inguinal region to the xiphoid region, the area was thoroughly washed again and disinfected using $2 \%$ chlorhexidine solution (Purit ${ }^{\circledR}$ saro life care, Nigeria). Local anaesthesia was achieved by inverted L block infiltration using $30 \mathrm{mls}$ of lidocaine with Adrenaline (Adrenalid ${ }^{\circledR}$ Shreechem pharmaceuticals, India) and the site was draped in a rectangular fashion. An oblique lower left flank skin incision was made, abdominal muscles were separated along their bellies by grid dissection, the gravid uterus was

Table 1. Patient's vital parameters on presentation

\begin{tabular}{|c|c|c|}
\hline Parameters & Patient values & ${ }^{*}$ Reference \\
\hline Temperature ${ }^{\circ} \mathrm{C}$ & 39 & $37.2-38.3^{\circ} \mathrm{C}$ \\
\hline Pulse rate (beats/min) & 28 & $28.0-44.0 \mathrm{~b} / \mathrm{m}$ \\
\hline $\begin{array}{l}\text { Respiratory } \\
\text { (cycles/min) }\end{array}$ & 20 & $10.0-24.0 \mathrm{c} / \mathrm{m}$ \\
\hline
\end{tabular}

\section{Radostitis 1983}

exteriorized (Plate III) and incision was made on the less vascularised portion avoiding the caruncles to deliver the fetus which was confirmed to be a double headed monster.

The uterus was closed by double row Cushing's suture pattern using size 2 chromic catgut (MEDTRUE ${ }^{\circledR}$ ) and six oxytetracycline boli (samoxine ${ }^{\circledR}$ Sam Pharmaceuticals, Nigeria ) were administered intra-uterine. The peritoneum and the three layers of abdominal muscles (Oblique
Table II. Patient's haemogram

\begin{tabular}{|c|c|c|}
\hline Parameters & $\begin{array}{l}\text { Patient's } \\
\text { value }\end{array}$ & $\begin{array}{l}\text { * Reference } \\
\text { values }\end{array}$ \\
\hline $\mathrm{Hb}(\mathrm{g} / \mathrm{dL})$ & 10.3 & $10.1-16.1$ \\
\hline $\mathrm{PCV}(\%)$ & 33 & $24-50$ \\
\hline $\begin{array}{ll}\text { Total } & \text { leucocytes } \\
\left(\mathrm{x} 10^{9} / \mathrm{L}\right) & \end{array}$ & 8.1 & $4-12$ \\
\hline $\begin{array}{l}\text { Neutrophils } \\
\left(\times 10^{9} / \mathrm{L}\right)\end{array}$ & $5.6^{*}(20)$ & $(0.4-6)^{*} 10-50$ \\
\hline $\begin{array}{l}\text { Lymphocytes } \\
\left(\mathrm{x} 10^{9} / \mathrm{L}\right)\end{array}$ & $5.1 *(65)$ & $(1.6-9) * 40-75$ \\
\hline Monocytes (x10 $\left.10^{9} / \mathrm{L}\right)$ & $0.44 *(5)$ & $(0.079) * 0-6$ \\
\hline $\begin{array}{l}\text { Eosinophils } \\
\left(\times 10^{9} / \mathrm{L}\right)\end{array}$ & $0.81 *(10)$ & $(0.12) * 0-0.78$ \\
\hline Basophils (x109/L) & $0 *(0)$ & $(0-086) * 0-3$ \\
\hline Bands $\left(\times 10^{9} / \mathrm{L}\right)$ & $0 *(0)$ & $0.0-0.1$ \\
\hline
\end{tabular}

abdominis interna, transversus abdominis and Oblique abdominis externa) were closed with simple continuous suture pattern using size 2 chromic catgut (MEDTRUE ${ }^{\circledR}$ ) (Plate IV).

The cutaneous muscles and superficial fascia were closed with subcuticular suture pattern using size 2 chromic catgut (MEDTRUE $^{\circledR}$ ) and the skin was closed with horizontal mattress suture pattern using size 2 silk (MEDTRUE ${ }^{\circledR}$ ). The surgical site was sprayed with Oxytetracycline (Oxyspray ${ }^{\circledR}$ Animal care, Nigeria) and oxytetracycline $20 \%$ (Tridox ${ }^{\circledR}$ L.A Farvet, Holland) at a dose rate of $20 \mathrm{mg} / \mathrm{kg}$ (total dose $7000 \mathrm{mg}$ ) was given intramuscularly. Daily evaluation and wound dressing of the surgical site was done and by day 7 post- surgery, the surgical site was in good condition with no suppuration. The healing was uneventful and the stitches were removed on day 10 post-surgery.

\section{DISCUSSION}

The common monsters causing dystocia are Schistosoma reflexus, perosomus elumbis, double or conjoined monsters and cyclopia (Johansson, 2014).In these conditions, either cranial or caudal parts of the body may be duplicated, the former being more common. Partial duplication of the cranial and caudal parts of the conjoined fetuses can occur (Astle, 2018).

Teratologic abnormal development or arrest in development of the embryo or fetus results in death or malformation of the antenatal individual (Abt et al., 2012 and Davis 2012). The underlying causes of monsters are only partially known.

They seem to occur most frequently in animal groups where genital disease are most severe and the clinical history of the female reveals previous genital disease (Auston \& Krueger, 2002). If the malformation involves only one organ or a part of the body, it is called anomaly. If the deformity is extensive, the individual is said to be a monster. Inherited 

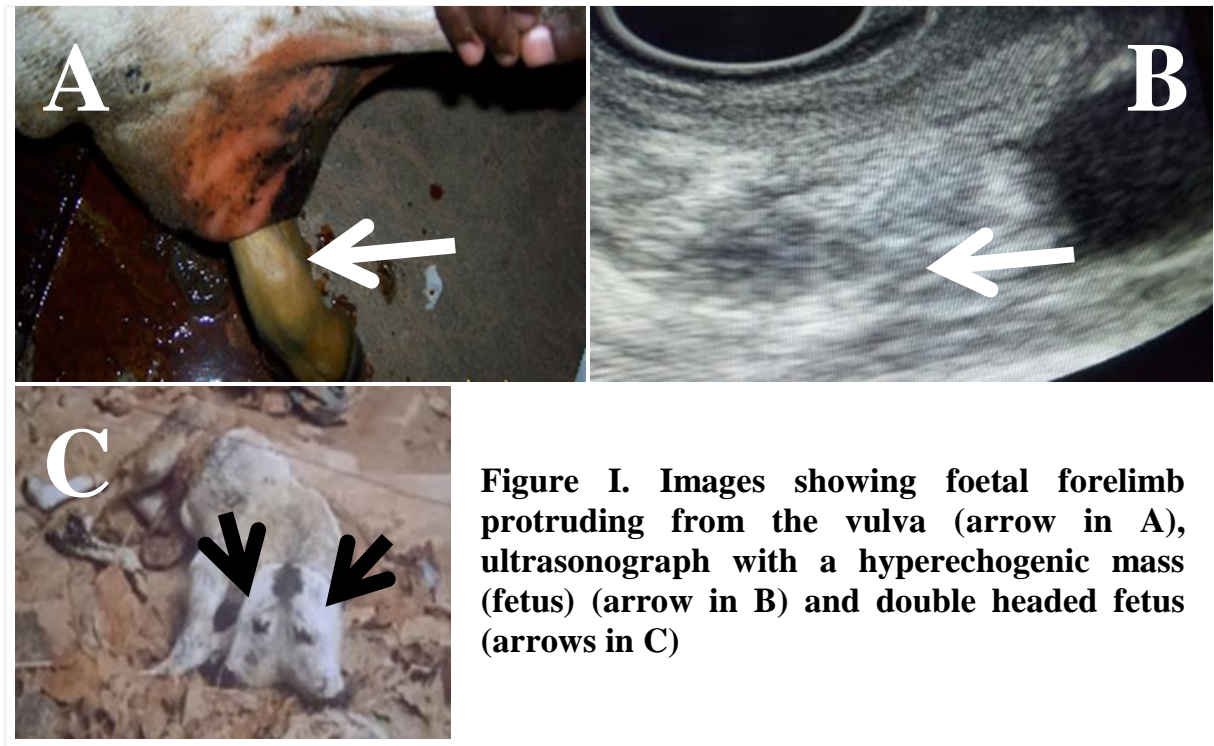

Figure I. Images showing foetal forelimb protruding from the vulva (arrow in A), ultrasonograph with a hyperechogenic mass (fetus) (arrow in B) and double headed fetus (arrows in C) anomalies of development which occur most commonly in cattle are usually due to a single autosomal recessive gene (Mcfarland \& Werber, 2013).

In an earlier report, Hugies et al (2009) demonstrated a significant association of the sire with the abnormal animals. Lauvergne and Cue (2018) reported 26 cases of ectromelia and concurrent ontocephalus in calves which were born in an artificial insemination center in France. The 5 sires of the 21 of these calves came from Friesland and were related to a bull which had sired similar calves.

When gestation continues beyond the normal term, monsters create an endless variety of obstetrical difficulties (Hartman, 2012). Normal parturition disposition are longitudinal anterior presentation, dorso-sacrum position and parturition posture that comprises extension of limbs and neck (Werber, 2013). Usually during parturition, the foetus is able to adjust and adapt to attain the aforementioned disposition. Unfortunately, in most monsters, the indiscriminate increase in foetal size reduces the room of the uterus. The foetus is usually incapable of proper adjustment due to limitation of space with the uterus to allow such movement. Hence leading to dystocia and prolong labor (Guilfol, 2011).

In Nigeria, records of foetal monsters in veterinary literature are few (Gyang, 1985). Therefore, it can be concluded to be a rare occurrence. Diagnosis was confirmed only by physical examination and rectal ultrasound. Caesarian section carried out saved the life of the dam. But because of the fetus was malformed, and the prolonged labor, it was very weak at delivery. It died few hours after delivery.

\section{CONCLUSION}

It was difficult to ascertain whether the genes responsible for this monstrous fetus was domiciled in the cow or the bull that mated the cow, hence the client was advised to withdraw the patient from the herd and salvage it when it fully recovered. It should be noted that the client decided to keep the patient despite our advice, the cow was mated and eventually calved a healthy bull.

\section{REFERENCES}

Abt, D.A., Crosllaw, J.E and Hare, W.C. (2012) Monocephalus dipygus parasiticus and other anomalies in calf. Journal of American Veterinary Medical Association. 141. 1068-1072 Astle, N.L. (2002) A living twoheaded calf. Veterinary Medicine. 43: 34-35.

Auston, K. \& Wearden, S. (2002) congenital tailessness in cattle. Journal Diary Science., , 41: 13591370 .

Davis, S.H.L. (2012) A bovine monster. Veterinary Medicine. 37:95-99.

Guilfol R.E. (2011) Dystocia due to gastrodidymus octipies. Veterinary Medicine. 40:28-30.

Lauvergne J.J., Cuq P.( 2018) Veterinary obstetrics and Genital diseases $3^{\text {rd }}$ ed, Pp., 38-48, Ithaca, New York.

Gyang E.O. (1985) Introduction to Large Animal Surgery. Ahmadu Bello University Press., Pp. 66-76.

Hugies, H.V. (2009) A case of duplication in a calf. Veterinary Journal. , 102:227-234.

Johansson, I. (2014) Reduced phalanges and curly coat, two mutant characters in native Swedish cattle. Hereditary, 28: 278-288.

Hartman, R.H. (2012) Monstrosity in a calf. Veterinary Medicine.,48:203-205.

Krueger E.W. (2002) Bovine dystocia due to Siamese twins. Journal of American Veterinary Medical Association., , 124:107-109.

Mcfarland L.Z. (2013) Spinabifida with myelomeningocele in a calf. Journal American Veterinary Medical Association., 134:32-34.

Werber H.W. (2013) an anomaly of the bovine fetus. Veterinary Medical Association., 111:276 -278.

Article history: Received: Nov. 11, 2021, Revised: Dec. 18, 2021, Accepted: Dec. 30, 2021 